\section{First Conference of the International Federation of University Women.}

THE International Federation of University Women held its first conference at Bedford College, London, on July $12-14$, and it has been interesting to note how thoroughly the Federation deserves its name. If Great Britain and the United States were the most numerously represented, as they are the founder nations, there were plenty of other nationalities to meet them. France, Spain, Italy, Holland, Belgium, the Scandinavian countries, CzechoSlovakia, India, and the Overseas Dominions of the British Empire had all sent their delegates to participate in the conference. The proceedings opened on the evening of July i2, when a large audience listened to speeches by Lord Grey of Fallodon, Prof. Caroline Spurgeon (Bedford College), Dean Virginia Gildersleeve (Barnard College, New York), and Prof. Winifred Cullis (the London School of Medicine for Women). Lord Grey emphasised the necessity for intercourse between the peoples of the world, and the women speakers outlined the means by which the International Federation intends to promote this necessary contact between the women of the universities of the world. Briefly, their aims are the establishment of travelling fellowships and international scholarships; the exchange of professors, lecturers, and students; the establishment of club-houses and other centres of international hospitality; and useful co-operation with the national bureaux of education in the various countries.

On the following days the foundations of the Federation were established. A constitution and by-laws were freely discussed and considerably amended before final adoption. The effect of these will be to establish a central office in London for general information, which will aperate in connection with Committees on International Relations set up in each country which is a member of the Federation. Officers have been elected for the ensuing two years, the president being Prof. Spurgeon; the vicepresident, Mrs. R. F. McWilliams, of Winnipeg; the treasurer, Mrs. Edgerton Parsons, of New York; and the secretary, Miss T. Bosanquet, assistant secretary to the Universities Bureau of the British Empire, 5o Russell Square, W.C.I.

Informal reports on the position of the higher education of women in the various countries represented were read, and steps will be taken to correlate the academic standards in the different universities.

The next meeting will be held in the summer of 1922. It is hoped that in the meantime each branch association of the Federation will work actively to further the aims of the Federation in its own country. The British Federation of University Women is losing no time in getting to work, and will initiate a campaign for the programme of the International Federation in the autumn.

\section{Insect Pests.}

I $\mathrm{N}$ connection with tropical agriculture, attention 1 has been directed to the question of the influence of the condition of the host-plant on infestation with sucking insects. It is believed that such pests as thrips on cacao and froghopper blight on sugar-cane can be held in check by increasing the resistance of the plant by improving agricultural conditions. In the Agricultural Neres (vol. xix., No. 464) it is claimed that the "mosquito blight" of tea (caused by a capsid bug of the genus Helopeltis) is affected in a similar No. 2647 , vOL. I05] way, and that the condition of individual tea-bushes determines the susceptibility to attack. The distribution of mosquito blight appears to be connected with soil conditions, and analytical data indicate that soils on which the pest is prevalent show similarities in the potash-phosphoric acid ratio, the addition of potash having an appreciable, though irregular, action in reducing the blight. Water-logging tends to encourage infestation, probably because the vitality of bushes grown on such areas is lowered; draining is the remedy advised in such cases. Acidity and poverty of soil are other factors which vitiate the health of the tea-bushes, so rendering them more liable to attack.

The spread of prickly pear in Australia is so rapid that large areas of land will continue to be thrown out of cultivation year by year unless some effective measure of control can be devised. It is estimated that the pest claims for its own I, 000,000 acres of fresh land per annum. Various methods of eradication have been tried, but destruction by mechanical or chemical means has proved too expensive for use on a large scale. The pear cannot be fed off to stock, and the manufacture of potash and paper from it has not proved to be commercially successful. A fourth line of attack-destruction by natural enemies-is now being followed up (Science and Industry, vol. ii., No. I). It is necessary to find some enemies of the prickly pear that will not attack other vegetation, as the introduction of "omnivorous vegetarians" would probably result in serious injury to other forms of plant-life. For this reason certain rodents, snails, and insects which are known to feed on prickly pear in America and Africa cannot be recommended for introduction into Australia. One insect, however, Coccus indicus, appears to feed exclusively on one form of pear, Opuntia monocantha, but unfortunately it will not feed upon the chief pest, $O$. inermis. It is recommended that experiments should be carried on to induce the insects to transfer their attention from one species to the other, if necessary by means of hybridising the pears. Other insects-bugs, flies, moths, and beetles-are known to feed upon one or other species of prickly pear, and it is possible that useful enemies might be introduced from Mexico and South America.

The loss caused by the jointworm flies of the genus Harmolita (Isosoma) in the United States runs into millions of dollars per annum, the wheat jointworm ( $H$. tritici) being the greatest devastator. W. J. Phillips (Bull. 808, Professional Paper, U.S.A. Dept. Agric.) has gathered together the available information and classified the species into groups that attack grain crops, cultivated grasses, and wild grasses. The two first groups cause considerable loss by the injury they entail to the crops. The members of the last group, however, may possibly be beneficial in an economic sense, as they provide intermediate hosts for the parasitic insects which prey upon the genus, the more important parasites being common to the majority of species of Harmolita. The life-histories of several species are described, together with the way in which injury is caused to the plants attacked. $H$. tritici causes the most serious losses, reducing the yield of wheat by as much as 50 per cent., the grains being somewhat small and shrivelled. $H$. grandis is also confined to wheat, and produces two generations in the year, but as it is easily controlled its powers of destruction can be kept in check. Breeding experiments indicate that each species is probably confined to a single host, as it has proved impossible to induce the more important forms to attack other crops than that with which they are normally associated. The jointworms are much subject to parasitic attacks, and for this reason do not often get quite 